\title{
Crystal Structure of 8-(3-Methyl-3-benzoylamino-butyl)-7-methoxycoumarin
}

\author{
L. Amirthasanjeevi, ${ }^{* 1}$ S. S. Rajan, ${ }^{* 1 \dagger}$ B. SRIDHaR, ${ }^{* 2}$ V. P. SanthanaKRIShnan, ${ }^{* 3}$ and \\ S. NARASIMHAN $* 4$
}

*1 CAS in Crystallography and Biophysics, University of Madras, Chennai-6000 025, India

*2 Indian Institute of Chemical Technology, Hyderabad-500 007, India

*3 Department of Chemistry, National Chung-Hsing University, Taiwan

*4 Asthagri Herbal Research Foundation, Chennai-600 059, India

\begin{abstract}
The title compound, $\mathrm{C}_{22} \mathrm{H}_{23} \mathrm{NO}_{4}$, is a derivative of osthol isolated from Imperatoria Osthruthium, known to possess an anti-inflammatory effect. The compound was crystallized in space group $P 2_{1} / c$ with cell parameters $a=11.383(3), b=$ 17.831(4), $c=9.802(2) \AA$, and $\beta=94.127(5)^{\circ}$. The final $R$ factor is 0.0629 . A modification of the compound has brought about changes in the conformation of $\mathrm{C} 7$ and $\mathrm{C} 8$. A ring motif, $\mathrm{R}_{2}{ }_{2}(8)$, is generated by $\mathrm{C}-\mathrm{H} \cdots \mathrm{O}$ and $\mathrm{N}-\mathrm{H} \cdots \mathrm{O}$ hydrogen bonding. The packing is also stabilized by a $\mathrm{C}-\mathrm{H} \cdots \pi$ interaction.
\end{abstract}

(Received October 19, 2007; Accepted January 8, 2008; Published on wed February 26, 2008)

Osthol, isolated from Imperatoria Osthruthium, exhibits antiinflammatory activity in rats, ${ }^{1}$ and is used in various medicinal preparations in India and also in the traditional Chinese system of medicine. ${ }^{2}$ Synthetic derivatives of osthol are used for hepatitis prevention, ${ }^{3}$ since osthol specifically increases the glycosylation of the hepatitis antigen and secretion of hepatitis $B$ virus in vitro. ${ }^{4}$ In this paper we report on the synthesis and crystal structure of a semi-synthetic derivative of osthol. It was prepared by a Ritter reaction ${ }^{5}$ and in the resulting derivative a double bond in the isoprenyl unit of osthol is modified to a single bond, and the final product also contains a benzamide group.

Benzonitrile was added to a solution of Osthol (100 mg / 0.41 mmol) dissolved in benzene, and the reaction mixture was cooled at $0^{\circ} \mathrm{C}$, followed by slow addition of sulfuric acid. The reaction mixture was stirred at room temperature for $2-3 \mathrm{~h}$ and was quenched after a complete disappearance of Osthol with a saturated solution of sodium bicarbonate. The final compound (Fig. 1) was extracted with ethyl acetate and dried over sodium sulfate. The compound was purified using column chromatography with $10 \%$ ethyl acetate in hexane as a mobile phase. Rod-shaped crystals were obtained using a slowevaporation technique from a mixture of ethyl acetate and hexane.

The crystal and experimental details are given in Table 1 . The

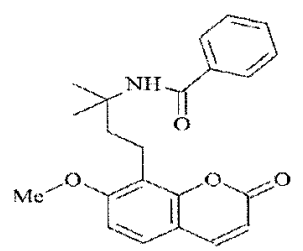

Fig. 1 Schematic diagram of the title compound.

$\dagger$ To whom correspondence should be addressed. E-mail: ssrajansai@yahoo.com structure was solved using direct methods, using SHELXS, and refined with SHELXL. Anisotropic refinement on all nonhydrogen atoms, with the hydrogen atoms included only in the structure factor calculations, gave a final $R$-factor of 0.0629 . The final atomic coordinates and temperature factors for all of the nonhydrogen atoms are given in Table 2. An ORTEP plot of the molecule at the $30 \%$ probability level is shown in Fig. 2.

In the above reaction, osthol is modified in such a way that a benzamide moiety becomes attached to the isoprenyl end, and the $\mathrm{sp}^{2}$ carbon atoms at $\mathrm{C} 7$ and $\mathrm{C} 8$ are converted to $\mathrm{sp}^{3}$ carbon atoms with $\mathrm{C} 7-\mathrm{C} 8=1.541(3) \AA, \mathrm{C} 9-\mathrm{C} 8-\mathrm{C} 7=116.0(2)^{\circ}$ and the torsion angles of $[\mathrm{C} 9-\mathrm{C} 8-\mathrm{C} 7-\mathrm{C} 14]=-70.2(3)^{\circ}$ and $[\mathrm{C} 9-\mathrm{C} 8-\mathrm{C} 7-\mathrm{C} 13]=52.8(3)^{\circ}$, respectively. The corresponding values in osthol ${ }^{6}$ are $1.327(3) \AA, 127.2(2)^{\circ},-1.61^{\circ}$ and $177.8(2)^{\circ}$, respectively. The relative orientation of the peptide unit

Table 1 Crystal and experimental data

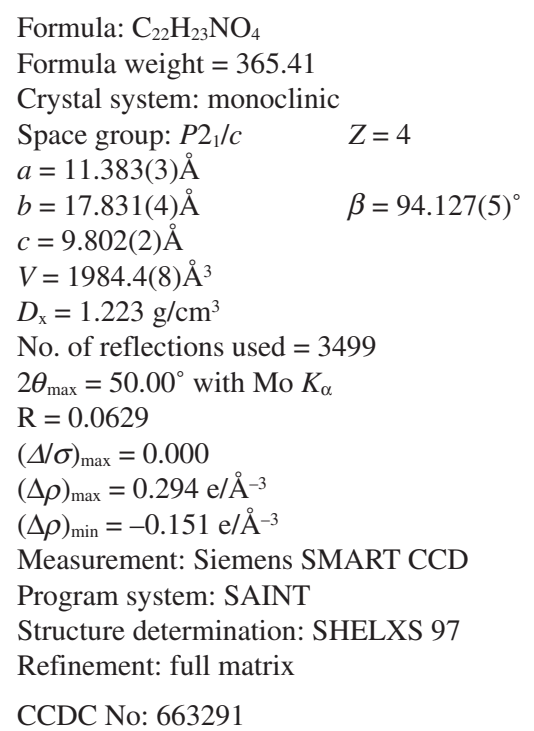


Table 2 Fractional coordinates $\left(\times 10^{4}\right)$ and equivalent isotropic thermal parameters $\left(10^{3} \times \AA^{2}\right)$ for non-hydrogen atoms

\begin{tabular}{ccccc}
\hline Atom & $x$ & $y$ & $z$ & $\mathrm{U}_{(\mathrm{eq})}$ \\
\hline $\mathrm{C}(1)$ & $3890(2)$ & $1136(2)$ & $1209(3)$ & $53(1)$ \\
$\mathrm{C}(2)$ & $2912(2)$ & $1299(2)$ & $1912(3)$ & $55(1)$ \\
$\mathrm{C}(3)$ & $3775(3)$ & $1234(2)$ & $-205(3)$ & $64(1)$ \\
$\mathrm{C}(4)$ & $1832(2)$ & $1535(2)$ & $1291(3)$ & $58(1)$ \\
$C(5)$ & $2708(3)$ & $1464(2)$ & $-870(3)$ & $74(1)$ \\
$\mathrm{C}(6)$ & $1759(3)$ & $1600(2)$ & $-124(3)$ & $71(1)$ \\
$\mathrm{C}(7)$ & $6880(2)$ & $1436(1)$ & $3334(2)$ & $44(1)$ \\
$C(8)$ & $5784(2)$ & $1583(2)$ & $2355(3)$ & $51(1)$ \\
$\mathrm{C}(9)$ & $5039(2)$ & $902(2)$ & $1951(3)$ & $55(1)$ \\
$\mathrm{C}(10)$ & $4745(4)$ & $1188(2)$ & $-2293(3)$ & $96(1)$ \\
$\mathrm{C}(11)$ & $881(3)$ & $1660(2)$ & $2136(4)$ & $73(1)$ \\
$\mathrm{C}(12)$ & $2124(3)$ & $1346(2)$ & $4150(4)$ & $81(1)$ \\
$\mathrm{C}(13)$ & $7677(2)$ & $823(2)$ & $2836(3)$ & $64(1)$ \\
$\mathrm{C}(14)$ & $6499(3)$ & $1235(2)$ & $4752(3)$ & $72(1)$ \\
$\mathrm{C}(15)$ & $1021(3)$ & $1576(2)$ & $3481(4)$ & $85(1)$ \\
$C(16)$ & $7994(2)$ & $2528(1)$ & $2471(2)$ & $40(1)$ \\
$\mathrm{C}(17)$ & $8512(2)$ & $3287(1)$ & $2789(2)$ & $40(1)$ \\
$\mathrm{C}(18)$ & $9418(2)$ & $3532(2)$ & $2029(3)$ & $53(1)$ \\
$\mathrm{C}(19)$ & $9905(3)$ & $4233(2)$ & $2226(3)$ & $67(1)$ \\
$\mathrm{C}(20)$ & $9478(3)$ & $4701(2)$ & $3180(3)$ & $72(1)$ \\
$C(21)$ & $8561(3)$ & $4478(2)$ & $3920(3)$ & $70(1)$ \\
$\mathrm{C}(22)$ & $8078(3)$ & $3768(2)$ & $3739(3)$ & $53(1)$ \\
$\mathrm{N}(1)$ & $7535(2)$ & $2155(1)$ & $3484(2)$ & $44(1)$ \\
$O(1)$ & $3033(2)$ & $1213(1)$ & $3316(2)$ & $69(1)$ \\
$O(3)$ & $2331(2)$ & $1253(2)$ & $5354(3)$ & $125(1)$ \\
$\mathrm{O}(2)$ & $4772(2)$ & $1083(2)$ & $-855(2)$ & $85(1)$ \\
$O(4)$ & $8003(2)$ & $2276(1)$ & $1299(2)$ & $52(1)$ \\
\hline & & &
\end{tabular}

$\mathrm{U}_{(\mathrm{eq})}=(1 / 3) \sum_{i} \Sigma_{j} U_{i j} a_{i} * a_{j}^{*}\left(\boldsymbol{a}_{i} \cdot \boldsymbol{a}_{j}\right)$.

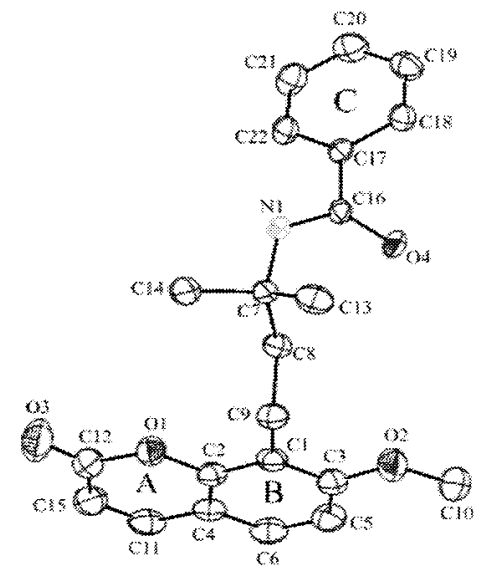

Fig. 2 Perspective view of the molecule, showing thermal ellipsoids at the $30 \%$ probability level.

(C7-N1-C16-O4-C17) with respect to the benzene ring $(\mathrm{C} 17 \cdots \mathrm{C} 22)$ is $31.4(1)^{\circ}$. The methoxy group at $\mathrm{C} 3$ is coplanar

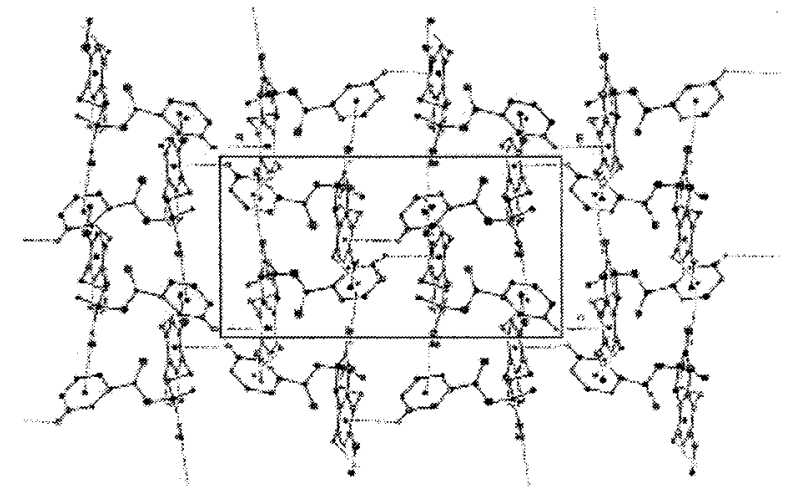

Fig. 3 View of the packing showing the $\mathrm{C}-\mathrm{H} \cdots \pi$ interactions.

with the fused benzene rings, as seen in osthol. The change in the conformation may be attributed to a bulky substitution at atom $\mathrm{C} 7$.

The angle between the benzopyran ring formed by the A \& B rings and the $\mathrm{C}$ ring is $83.8(1)^{\circ}$. The atoms of the functional group show higher thermal parameters compared to those of the coumarin ring. Two such chains run in opposite directions. The molecular packing in the crystal structure is further stabilized by C-H. $\cdots \pi$ interactions (Fig. 3 ). The molecules in the crystal lattice are packed together via $\mathrm{C}-\mathrm{H} \cdots \mathrm{O}(-1+x, y, z)$, and $\mathrm{N}-\mathrm{H} \cdots \mathrm{O}(x,-y+1 / 2, z+1 / 2)$ hydrogen bonds with a head-to-tail fashion. A ring set motif, $\mathrm{R}_{2}{ }_{2}(8)$, is formed through these hydrogen bonds.

\section{Acknowledgements}

LA thanks the University of Madras for financial support.

\section{References}

1. J. Liu, W. Zhang, L. Zhou, X. Wang, and Q. Lian, Zhong yao cai., 2005, 28, 1002.

2. R. Liu, S. Zschocke, E. B. Reininger, and R. Bauer, Planta Med., 1998, 64, 525 .

3. T. Okamoto, T. Kobayashi, and S. Yoshida, Med. Chem., $\mathbf{2 0 0 7}, 3,35$.

4. R. L. Huang, C. C. Chen, Y. L. Huang, D. J. Hsieh, C. P. $\mathrm{Hu}, \mathrm{C} . \mathrm{F}$. Chen, and C. Chang, Hepatology, 1996, 24, 508.

5. J. J. Ritter and P. P. Minieri, J. Am. Chem. Soc., 1948, 70, 4045.

6. T. Borowiak and I. Wolska, Acta Cryst., 1989, C45, 620. 